\title{
AN OUTBREAK OF HAEMORRHAGIC SEPTICAEMIA IN THE NAVITHANVELI VETERINARY RANGE IN AMPARA DISTRICT, SRI LANKA
}

\author{
M.W.D.C. Weerathunga ${ }^{1}$, J.K.H. Ubeyratne ${ }^{2}$ and M.A.Nadheer ${ }^{1}$ \\ ${ }^{1}$ Department of Animal Production and Health, Ampara, Sri Lanka \\ ${ }^{2}$ Veterinary Research Institute, Gannoruwa, Peradeniya, Sri Lanka
}

\begin{abstract}
SUMMARY: Haemorrhagic septicaemia (HS) is a major diseases of bovines in Sri Lanka before 2005. The disease is endemic in dry zone where clinical incidences occur with the onset of monsoon. An outbreak of HS occurred in twenty 1-3 year old local buffaloes of which 15 died, in mid-October 2016 in Navithanveli veterinary range in Ampara District. The disease continued and another 13 buffaloes and 3 cattle died. Clinical and necropsy findings and laboratory identification confirmed that the causative organism was Pasrerella multocida serotype B:2. Outbreak was controlled with treatment and vaccination of all susceptible animals. This is the first report of the re-emergence of $P$. multocida after 2000 in Ampara district.
\end{abstract}

\section{INTRODUCTION}

Hae mor rha gic Sep tic aemia (HS) is a fat al septicaemic disease of bovines where water buffaloes are more susceptible than cattle (Bain et al., 1982). It is caused by $P$. multocida, a Gram negative cocobacilli which colonize the nasopharynx (Wijewardana, 1992; Tabatabaei et al., 2007). Specific serotypes of $P$. multocida B: 2 and E: 2 cause HS in Asia and Africa respectively (Benkirane, 2002; Carter, 1955). $P$. multocida can survive for some period in soil or water (Bain et al., 1982) where viability will be reduced after 2-3 week. Direct contact with infected animals and fomites are the main sources of transmission of the causative organism and bovines are infected due to ingestion of contaminated pasture or water. In endemic areas, up to $5 \%$ of cattle and water buffalo may act as carriers (DeAlwis., 1992) and harbour organism in their nasopharynx. Stress, poor nutrition, close herd, wet humid weather leads to spreading of the disease to buffaloes and cattle during paddy cultivation in the north east monsoon. Furthermore moist environment facilitate the longer survival of the organism outside the host (De Alwis, 1999)

Most cases in cattle and buffaloes are acute or per acute with signs of depression, fever, salivation and a serous nasal discharge. Furthermore they develop oedematous swellings in the pharyngeal region which spread to the ventral cervical region and brisket, causing hyperaemic mucous membranes and respiratory distress. Moreover, animals collapse and die 6-24 hours after appearence of clinical signs (De Alwis et al., 1992). Mortality is nearly $100 \%$ unless the animal is treated very early with antibiotic during the pyrexic stage. Sanitary measures and vaccination should be carried out in-order to minimize the occurrence of the disease (Benkirane and De Alwis, 2002). Vaccination using inactivated culture has been used to overcome the disease in many countries and in Sri Lanka. Vaccination must initiate at 4 months and continued annually in Sri Lanka (DeAlwis., 1999)

HS is seen in tropical countries in Africa, South and South East Asia, Southern Europe and Middle East. HS is a devastating alarming problem in cattle and buffaloes in Asia because of economic loss and crop redundant (De Alwis, 1999). HS was first reported in 1911 in Sri Lanka but epidemics occurred in mid 1950s with 5000 deaths of cattle and buffaloes. However, vaccination started in 1957 but annual vaccination was inaugurated in 1984 in Sri Lanka (De Alwis, 1992). Consequently in the epidemics reported in early 1980 s and 1990 s, the mortality had declined progressively (FAO, 1991; De Alwis, 1999). De Alwis reported HS was endemic in 13 districts covering two-third of the island during 1980s. Sri Lanka has self-declared HS on $12^{\text {th }}$ December 2012 following massive national efforts through passive, active and serological surveillance according to OIE terrestrial animal health code (OIE, 2012). This article describe the reoccurrence of HS in water buffaloes and cattle in Navithanveli veterinary range in Ampara District probably the first re-emerging episode in the Ampara district.

\section{MATERIALS AND METHODS}

\section{Outbreak location}

Navithanveli is situated in the Ampara District bordering from East and West by Kalmunai (Kittange Lake) and Uhana range, South and North by Samanthurai and Thumberkerny (Batticalo District). Navitanveli experience a long dry period which extends from February to November. Main occupation of the 
people is paddy cultivation which depends on North east monsoon extending from November to February. The first incidence occurred in the Chavalakada Grama Niladhari (GN) area adjacent to the Kittange lake. Furthermore cases were reported from Annamalai 01, Annamalai 02 and Chavalakada GN divisions (Figure 1) where farmers rare buffaloes and cattle with free grazing.

\section{History and clinical signs}

First occurrence was reported with the sudden death of 15 local buffaloes including eight females and seven males on $17^{\text {th }}$ October 2016 with the onset of North east monsoon. However, there were five local buffaloes showing clinical signs of depression, severe respiratory distress, submandibular, ventral cervical and brisket oedema, hyperaemic mucous membranes, fever $\left(106^{\circ} \mathrm{F}\right)$ and hyper salivation (Figure 2). All the affected animals were within the age group of 1-3 years. Furthermore the outbreak continued with sudden death of 5 buffaloes in adjacent herds (Chavalakada, Annmalai 01 and Annmalai 02) where 28 showed clinical signs. Moreover the outbreak spread to the cattle herds in Chavalakada and Annmalai 01, with 24 clinically affected animals of which 3 died in a short period of time. The condition in cattle was less severe than buffaloes as they have shown only hyperaemic mucous membrane, hyperthermia and respiratory distress.

\section{Laboratory Investigation}

\section{Bacteriological analysis}

Post mortem on 3 buffaloes and one cattle was conducted in $18^{\text {th }}$ and $25^{\text {th }}$ October. Samples of heart blood, tissue samples of lung, liver and spleen were collected and dispatched in ice to the Central Veterinary Investigation Centre at Veterinary Research Institute, Gannoruwa.

Samples were cultured aerobically on $5 \%$ blood agar and on Mac Conkey agar plates and incubated at $37^{\circ} \mathrm{C}$ for 24 hours. Positive cultures were subjected to biochemical tests (Indole, Oxidase and Nitrate) and mouse inoculation (subcutaneous or intra-peritoneal route). Further confirmation was done by serotyping, agglutination test with serum raised against Pasturella multocida B: 2 followed by agar gel precipitation test.

\section{Serogroup identification by Polymerase Chain Reaction}

\section{DNA extraction}

Genomic DNA isolation from samples were performed using the tissue sample protocol of the QIA amp DNA (QIAGEN, Germany) purification mini kit according to the manufacturer's instructions with a loop full of cells (culture) suspended in $200 \mu 1$ of distilled water. Samples were centrifuged for 5 minutes at $3000 \mathrm{rpm}$. The supernatant was removed completely and discarded.

\section{Mulitplex PCR using HS causing type B}

The multiplex PCR was performed in a GeneAmp PCR system 9700 (Applied Biosystems) thermal cycler using the QIAGEN multiplex PCR kit. Primer sequences (Townsend et al., 1998) were used for P. multocida specific KMT1T7: 5'-ATC-CGC-TAT-TTA-CCC-AGTGG-3' KMT 1SP 6: 5'-GCT-GTA-A AC-GAA-CTCGCC-AC-3', P. multocida type A specific primer RGPMA5: 5'-AAT-GTT-TGC-GAT-AGT-CCG-TAG-A3' RGPMA6: 5'-ATT-GTT-TGC-GAT-AGT-CCG-TAGA-3' and HS-causing type-B-specific KTT72: 5'-AGGCTC-GTT-TGG-ATT-ATG-AAG-3' KTSP61: 5'-ATCCGC-TAA-CAC-ACT-CTC-3' des cribed in OIE terrestrial manual 2012.

PCR reaction consisted with $1 \times$ PCR buffer, $200 \mu \mathrm{M}$ each deoxynucleotide triphosphate (dNTP), $2 \mathrm{mM}$ $\mathrm{MgCl}_{2}, 3.2 \mathrm{pmol}$ of each primer and $1 \mu \mathrm{l}$ Taq DNA polymerase. PCR was done in a final volume of $25 \mu 1$ with initial denaturing at $95^{\circ} \mathrm{C}$ for 5 minutes, 30 cycles of denaturing at $95^{\circ} \mathrm{C}$ for 1 minute, annealing at $55^{\circ} \mathrm{C}$ for 1 minute and extension $72^{\circ} \mathrm{C}$ for 1 minute, with a final extension at $72^{\circ} \mathrm{C}$ for 7 minutes. Distilled water (QIAGEN) was used as a negative control. A volume of 5 $\mu 1$ of each sample was electrophoresed on a $2 \%$ agarose gel in $1 \times$ Tris-acetate running buffer (TAE) at $4 \mathrm{~V} / \mathrm{cm}$ for 1 hour. The gel is stained with $1 \%$ ethidium bromide and DNA fragments are viewed by UV trans illumination.

\section{Antimicrobial susceptibility test}

Antimicrobial susceptibility test was carried out by the disc diffusion method according to the manuals of clinical laboratory standard institute. Cephalexin $(30 \mu \mathrm{g})$, Amoxicillin clavulunate (augmentin) (30 $\mathrm{g})$, Tetracycline $(30 \mu \mathrm{g})$, Cloxacillin $(10 \mu \mathrm{g})$ and Penicillin $(10 \mu \mathrm{g})$, Erythromycin $(5 \mu \mathrm{g})$, Neomycin $(30 \mu \mathrm{g})$ and Enrofloxacin $(5 \mu \mathrm{g})$ discs (HIMEDIA, India) were used for the test.

\section{RESULTS AND DISCUSSION}

\section{Necropsy findings}

Necropsy examination of three buffaloes revealed congested lungs, petechial haemorrhages on cardiac parenchyma, sub-epicardial adipose tissue, serosal surface of abdominal organs, and blood tinged fluid in the body cavities (Figure 3 ).

\section{Laboratory findings}

Smooth, greyish glistening translucent colonies on blood agar revealed characteristics similar to that of $P$. multocida colonies. Leishman stain indicated Gram negative bipolar short coccobacilli. There was no growth on MacConkey agar. Indole, oxidase and nitrate biochemical tests were positive. Further, in mouse inoculation test death occurred after 18 hours and gram negative bipolar coccobacilli were isolated from heart blood. Serotyping revealed that the isolate agglutinated with specific serogroup $P$. multocida type B: 2 . Pathogenic strain was confirmed as P. multocida serotype $B$ by multiplex PCR with the amplification product sizes of $457 \mathrm{bp}, 620 \mathrm{bp}$ and $720 \mathrm{bp}$ respectively (Figure 4). Conventional bacteriological test, serotyping and molecular findings confirmed the isolate is $P$. multocida 


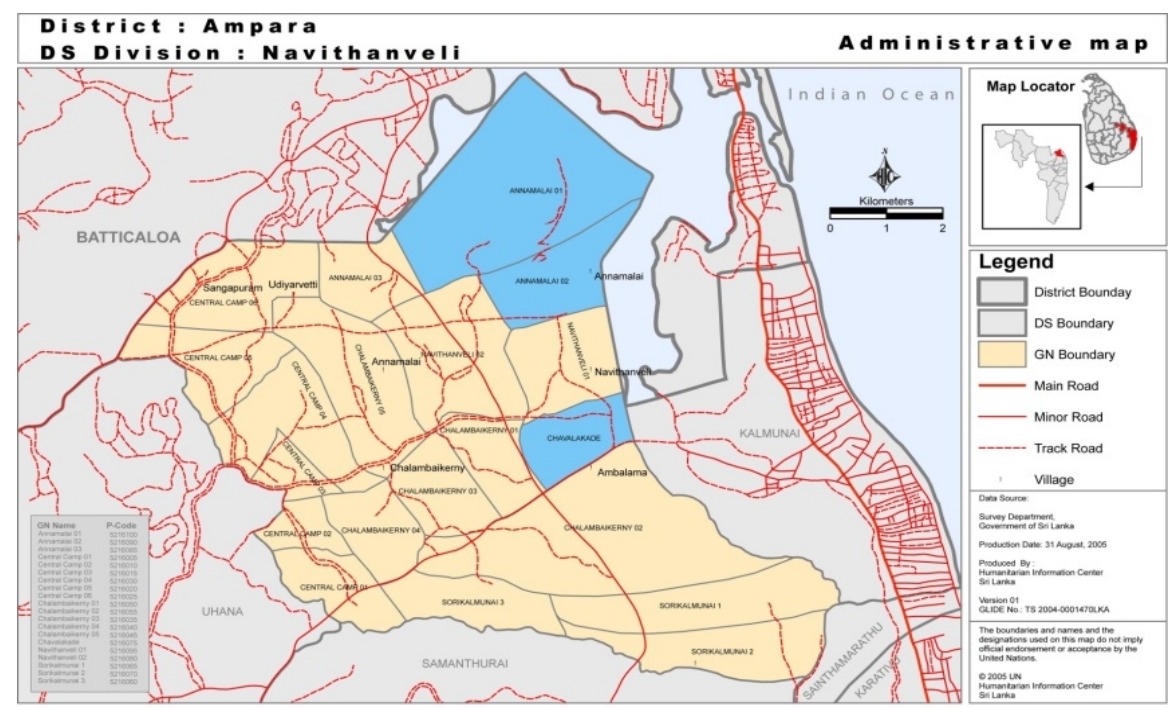

Figure 1. Geogrophical distribution of Navithanveli veterinary Divisional secretarial division (Blue colour indicate outbreak locations) Source; Navithanveli Administrative map
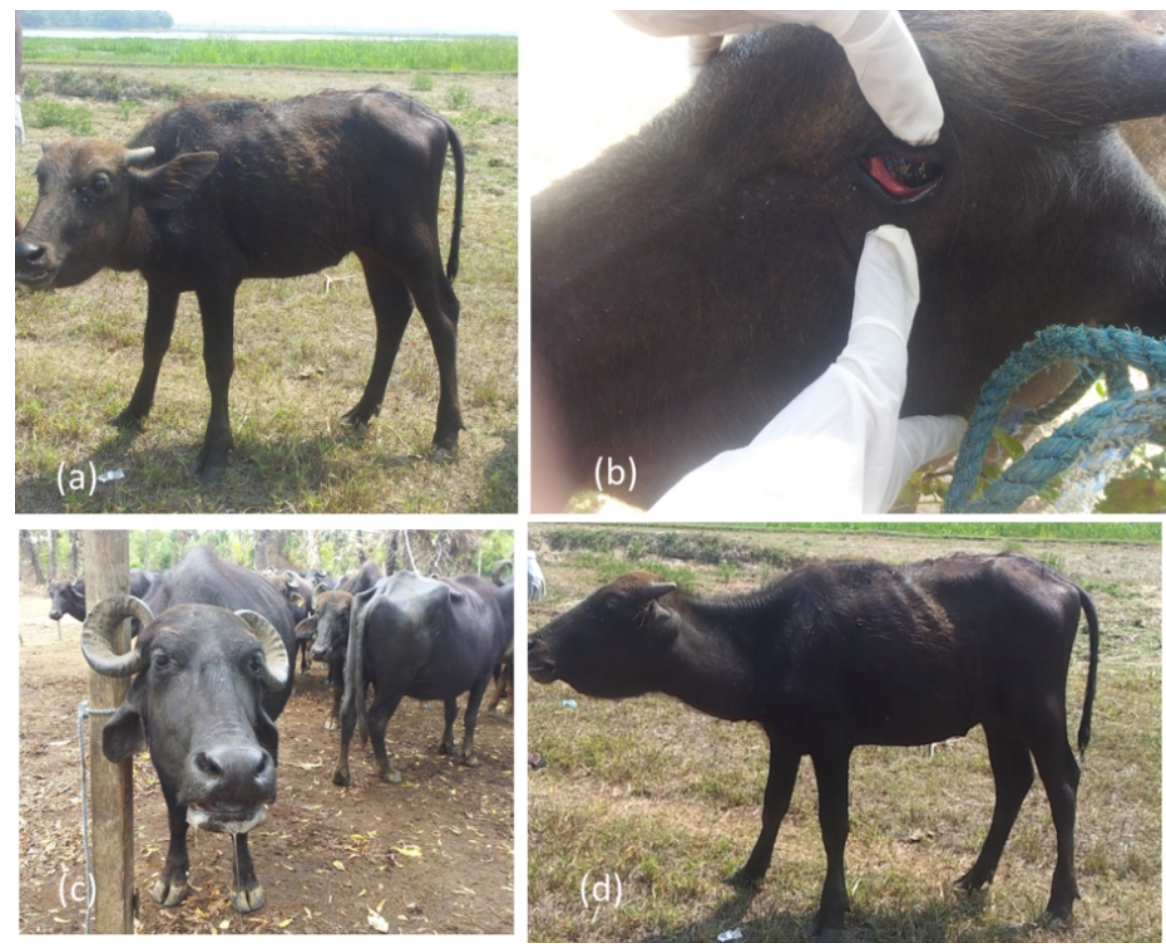

Figure 2.Clinical cases of HS affected buffaloes ( $a$, depressed animal; b, congested mucous membrane; $\mathrm{c}$, hypersalivation and $\mathrm{d}$, oedema in submandibular, cervical region towards brisket)

serotype B: 2. This organism was sensitive for tetracycline, penicillin, cephalexin, amoxicillin clavulunate (augmentin) and cloxacillin.

\section{Outbreak control}

The index cases were tentatively diagnosed as HS by the clinical signs and necropsy findings. Thereafter treatment was initiated with broad spectrum antibiotic oxytetracycline $(20 \%)$ at the rate of $10 \mathrm{mg} / \mathrm{kg}$ and dexamethasone $0.1 \mathrm{mg} / \mathrm{kg}$ intramuscularly. At the same 


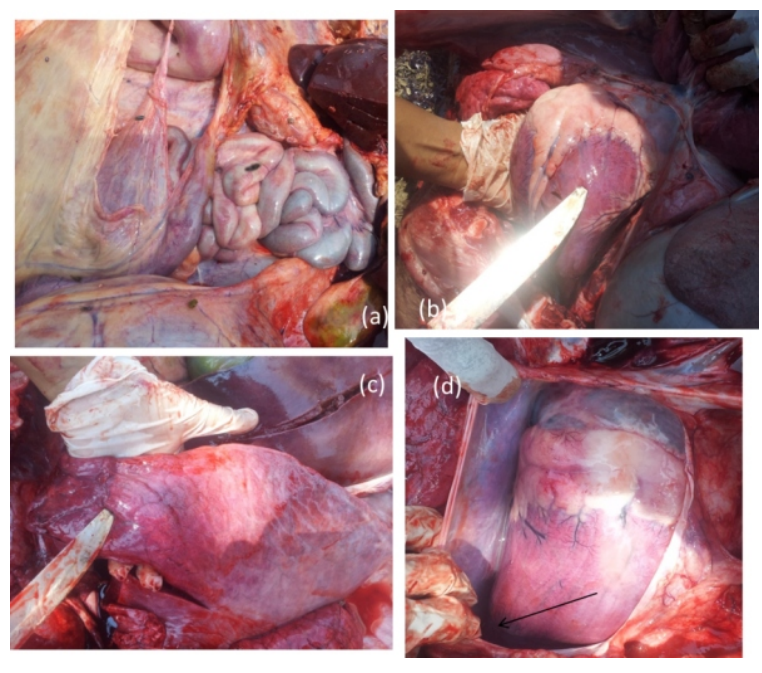

Figure 3. Necropsy findings (a, haemorrhages at the serosal surface of intestine; $b$, peticheal haemorrhages on cardiac parenchyma; c, congested lung and d, pericardial effusion)

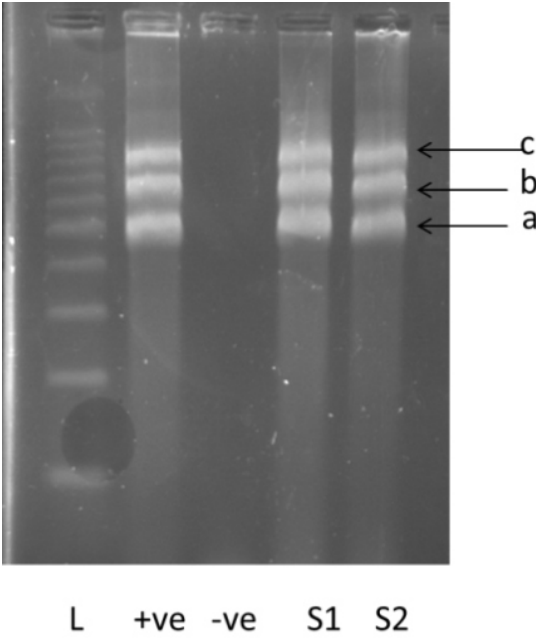

Figure 4. Gel electrophoresis image of multiplex PCR using samples from one animal (L:100bp ladder, Lane 1: positive control, Lane 2: negative control, Lane 3: S1, heart blood, Lane 4: S2, lung: aP.multocida species specific $457 \mathrm{bp}$, bHS type B specific $620 \mathrm{bp}$ and c- HS serogroup B specific 720bp) time all the susceptible animals in herds were vaccinated with inactivated $P$. multocida combined with alum adjuvent as a control measure. Following early treatment, 24 buffaloes and 21 cattle successfully recovered but 4 buffaloes died despite treatment. Dead carcases were deeply buried and infected areas were burnt with straw. Furthermore routine preventive vaccination was initiated against $\mathrm{HS}$ in Ampara District to prevent further occurrence of the disease.

\section{DISCUSSION}

Outbreaks of HS usually occur in many Asian and African countries resulting in high mortality and morbidity (Bain et al., 1982; De Alwis, 1992). According to this outbreak, HS occurred with the onset of Northeast monsoon in Navithanveli veterinary range from October to February. Hot and humid climatic condition is a major contributory factor in this outbreak of HS where high environmental temperature facilitates the multiplication of the bacteria outside the host (Hajikolaei et al., 2008). This is similar to the observations made by De Alwis (1992). Majority of the affected animals in this outbreak were buffaloes where 25 died and among them 20 were from the same herd. These affected buffaloes were mainly reared for paddy cultivation during north east monsoon in the area where they freely roam in the lands. Harvesting, lack of food, overcrowding, and poor hygiene are stress factors to the animals that facilitate harbouring of organisms in their nasopharynx similar to the observations made by De Alwis (1992). Furthermore, paddocking together at night, using common grazing land and water resource are involved in spreading of the disease to adjacent buffaloes and cattle herds (Chavalaka, Annmalaia 01 and Annamalai $02 \mathrm{GN}$ division) during this outbreak.

Under field conditions, HS is usually diagnosed on the basis of clinical signs and symptoms (Khan et al., 2006). Early treatment depends on the early diagnosis of the disease (De Alwis, 1999). Respiratory distress, dyspnoea, high temperature, reduced appetite, restlessness and hypersalivation were present in affected buffaloes similar to that observed by Sheikh et al., (1996).

HS is effectively treated by broad spectrum antibiotics. According to Benkirane and De Alwis (2002), animals can be recovered if they have been treated in the very early stage of the disease. Penicillins are the drug of choice of HS because the causative organism is sensitive to this $\beta$-lactam antibiotics (Kristinsson and Adam, 2007; Pedersen et al., 2009). This isolate was sensitive for wide range of antibiotics however, tetracycline was used for treatment and 45 animals who developed clinical signs recovered after treatment. Nevertheless four animals died due to severity of the infection. Early intervention together with treatment and vaccination overcome the outbreak of HS within short time period.

P. multocida produces endotoxins which causes the toxaemia (Horadagoda et al., 2001; Zafar et al., 2010). During necropsy, it was observed in the present outbreak that haemorrhages of abdominal organs, heart, congested 
lungs were present in all carcasses and similar type of lesions has been reported (Sheikh et al., 1996). The animals died within 4-6 hours after showing the clinical signs. According to DeAlwis (1992) necropsy findings depend on the duration of the clinical sings. Per acute cases rarely develop post-mortem lesions.

In peracute cases, buffalo die without any clinical signs in common grazing lands and near water bodies which provide source of infection for other animals (Sharee and Salim, 1991) Carcasses left on grazing lands and near water bodies lead to further spreading of the disease in this outbreak because farmers were reluctant to do proper disposal of carcasses due to heavy economic loss and lack of awareness. Therefore, awareness programmes were conducted to the farmers to encourage carcass burning and restrict animal movements.

Due to the annual vaccination programmes and improved diagnostic facilities, HS was not reported in last 11 years in Sri Lanka and self-declaration for HS was done in 2012. Even though the prophylactic vaccination for $\mathrm{HS}$ is carried out in the country, vaccination had not been continued in Navithanveli range for several years. That might be the reason for reduced immunity among animals. During an outbreak it is preferred to initiate vaccination to entire herds irrespective of previous vaccination history (Benkirane and De Alwis, 2002) and it was practiced soon after this outbreak in the Navithanveli veterinary range. It was locally produced HS alum precipitated vaccine containing killed whole culture of $P$. multocida. Moreover, prophylactic vaccination should be continued with oil adjuvant vaccine for long term immunity (De Alwis, 1992). Subsequently cattle and buffalo transport was withheld and farmer awareness programmes were initiated to minimize the condition.

\section{CONCLUSION}

This is the first re-emerging outbreak in Navithanveli range, however previous outbreaks were not documented in history. Early detection methods, restricting movements of animals, routine preventive vaccination programmes and awareness programmes are suggested to prevent further occurrence of the disease.

\section{ACKNOWLEDGEMNET}

The authors would like to express their gratitude to the technical and support staff members of veterinary office Navithanveli and Central veterinary investigation centre, Veterinary research Institute, Gatambe for assisting and laboratory investigation.

\section{REFERENCES}

Bain, R.V.S., De Alwis, M.C.L., Carter, GR., Gupta, B.K. (1982). Haemorrhagic septicaemia. FAO Animal Production and Health Paper No. 33, Rome,
Italy

Benkirane, A., De Alwis, M.C.L. (2002). Hae mor rha gic septicaemia, its significa nce, prevention and control in Asia. Veterinary Medicine Czech, 47: 234240.

Carter G.R. (1955). A haemagglutination test for the identification of serological types. American Journal of Veterinary Research, 16, 481484.

De Alwis, M.C.L. (1992) Haemorrhagic septicaemia. A general review. British Veterinary Journal, 148: 99112

De Alwis, M.C.L., (1999). Haemorrhagic septicaemia. Australian Centre for International Agricultural Research (ACIAR) Monograph No 57, Canberra, Australia, pp:1-34.

https://www.oie.int/doc/ged/D12732 (2013). Self declaration from Sri Lanka of its disease status of freedom from Haemorrahic Septicaemia, The OIE and its partners, $\mathrm{p}: 54-55$

Khan, A., Saddique, U., Ahmad, R., Khan, H., Mohammad Y., Zubair, M. (2006). Sero surveillance of hemorrhagic septicemia in cattle and buffaloes in district Malakand, NWFP. Journal of Animal and Veterinary advances 5: 912-915.

Kristinsson, G., Adam, H.M. (2007). Pasteurella multocida infections. Pediatrics in Review, 28: 472473

Hajikolaei, M.R.H., Ghorbanpour, M., Seyfiabadshapouri, M.R., Rasooli, A., Moazenijula, G.R., Ebrahimkhani, D. ( 2008). Study on the prevalence of Pasteurella multocida carriers in slaughtered cattle and relationship with their immunity status at Ahvaz abattoir. Journal Veterinary Research, 63: 25-29

Horadagoda, N.U., Hodgson, J.C., Moon, G.M., Wijewardana, T.G, Eckersall, P.D. (2001). Role of endotoxin in the pathogenesis of haemorrhagic septicaemia in the buffalo. Microbial Pathogenesis, 30: 171178

Pedersen, K., Hammer, A.S., Sørensen, C.M., Heuer, O.E. (2009). Usage of antimicrobials and occurrence of antimicrobial resistance among bacteria from mink. Veterinary Microbiology, 133: 115-122.

Sharee, A.A., Salim, N. (1991). The epidemiology of haemorrhagic septicaemia in cattle and buffalo in Malaysia. A paper presented at the Fourth International Workshop on Haemorrhagic Septicaemia, 11-15 February, 1991. Kandy, Sri Lanka.

Sheikh, M.A., Anzam M., Shakoori, A.R. (1996). Observations on hemorrhagic septicemia in Pakistan livestock. Journal of Veterinary Medicine, B,Infectious diseases and Veterinary Public Health 43: 293-304.

Tabatabaei, M., Moazzeni Jula, GR., Jabbari, A.R., Esmailzadeh, M. (2007). Vaccine efficacy in cattle against hemorrhagic septicemia with live attenuated aroA mutant of Pasteurella multocida B: 2 strain. Journal of Cell and Animal Biology, 1: 62-65. 
Townsend, A., DeMarie, S., and Hendrickson, A. (1998). Virtual teams: Technology and the workplace of the future. Academy of Management Executive, 12(3): 1729.

World Organisation for Animal Health (2012). Terrestrial Animal Health Code. OIE, Paris.

World Organisation for Animal Health (2012). Manual of Diagnostic Tests and Vaccines for Terrestrial Animals. OIE, Paris

Wijewardana, T.G., (1992). Haemorrhagic septicaemia. Reviews in Medical Microbiology, 3: 5963.
FAO (1991). Proceedings of the Fourth International Workshop on Haemorrhagic Septicaemia, February 1991, Kandy, Sri Lanka.

Zafar, M.A., Muhammad, G., Iqbal, Z. and Riaz, M. (2010). Effects of hypertonic saline solution on clinical parameters, serum electrolytes and plasma volume in the treatment of haemorrhagic septicaemia in buffaloes. Pakistan Veterinary Journal 30: 95-99. 